\title{
Impact of COVID-19 on coronary artery surgery: Hard lessons learned
}

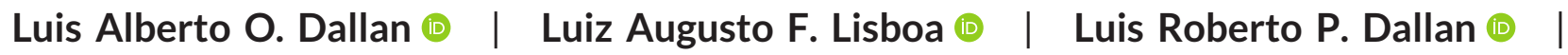 \\ Fabio B. Jatene (1)
}

Department of Cardiovascular Surgery, Heart Institute from University of São Paulo Medical School (InCor), São Paulo, São Paulo, Brazil

Correspondence

Luis Alberto O. Dallan, Dr. Enéas de Carvalho Aguiar, 44, Pinheiros, São Paulo, SP 05403-900, Brazil.

Email: dcidallan@incor.usp.br

Since March 11th, 2020 when coronavirus disease 2019 (COVID-19) was declared a pandemia, hospitals had to be adapted quickly to increase the assistance capacity for a large part of the population that needed hospitalization for severe acute respiratory syndrome coronavirus 2 (SARS-CoV-2) infection. ${ }^{1,2}$ Major disruptions on routine hospital services have occurred, with health professionals needed to assume functions beyond their usual routines and beds were adapted for intensive care due to the increased demand in the treatment of severe acute respiratory failure. Cardiovascular surgery was particularly affected by the coronavirus outbreak, since most of the elective surgeries were canceled and intensive care unit beds, normally dedicated to the postoperative period of cardiac surgery, were transferred to patients with COVID-19. ${ }^{3-5}$

In this context, Kalil and $\mathrm{Col}^{6}{ }^{6}$ examine the impact of the COVID-19 pandemic in the number of procedures and death rate of coronary artery bypass graft (CABG) performed in 2020 in Brazil. They analyzed patients undergoing CABG in the public health system between 2008 and 2020. The data were collected from DATASUS, the data processing system of the Brazilian Ministry of Health, which collects information from every patient who needs in-hospital care and was admitted to a public hospital. Patients operated on the private system were not captured in the database and were excluded from the analysis. The results showed that in 2020, during the pandemic period, there was an average reduction of $25 \%$ in the number of CABG performed in Brazil, with the majority of procedures (75\%) being performed in the south and southeast regions of the country. Regarding postoperative mortality, they observed an opposite effect with an increase in mortality from $5.6 \%$ to $6.3 \%$ during this pandemic period. ${ }^{6}$

This study has some limitations due to results extracted from an administrative database, good for epidemiological analysis, such as gender, age, number and type of surgeries performed. Considering the reduction in surgical volume during the pandemic period, surgical status was analyzed altogether (whether elective, or urgent or emergency $\mathrm{CABG}$ ), expressing a general view of the situation.

Brazil was the epicenter of the coronavirus outbreak in Latin America and other publications from Brazil showed different and more detailed results in relation to the pandemic period. ${ }^{7,8}$ One by Omar et al. ${ }^{7}$ who used data from the São Paulo Registry of Cardiovascular Surgery, a multicenter registry, showed a 60\% reduction in surgical CABG volume during COVID-19 pandemic. Regarding mortality, CABG surgeries had a 2.8 -fold increased mortality risk $(95 \%$ confidence interval $[\mathrm{Cl}]: 1-7.6, p=.041$ ), patients who evolved with COVID-19 had a 11-fold increased mortality risk (95\% Cl: 2.2-54.9, $p<.003$ ), rates of morbidities and readmission to the intensive care unit, ${ }^{7}$ compared to 2019.

In our own series at the Heart Institute University of Sao Paulo Medical School, Brazil, we observed a $65.8 \%$ reduction in cardiac surgery volume in 2020 , during the pandemic period, and $2 / 3$ of these were urgent or emergency procedures. Regarding the CABG in-hospital mortality, there was increased from 1.2\% (2019) to $3.0 \%$ (2020) among elective procedures and from $4.5 \%$ (2019) to $18.2 \%$ (2020) among urgent or emergency procedures. Patients who had postoperative COVID-19, the in-hospital mortality rate was significantly higher (38.5\%).

Other publications reported a reduction in surgical volume of more than $70 \%$ during the peak disruption due to COVID-19. ${ }^{4,9}$ Salenger et al. ${ }^{10}$ reported that the volume of cardiac surgery fell to $54 \%$ of baseline after the restrictions were implemented and they also estimated a necessity of 2.5 times increase in numbers of procedures in post-COVID-19 era to restore balance to elective surgeries waiting lists.

In 2020, from January 1st to March 31st, the COVIDSurg collaborative, a multicentric cohort of surgeries performed in 24 countries and 235 hospitals, reported that nonelective procedures corresponded to $75 \%$ of the surgeries with $24 \%$ mortality. 
Among 50 patients who underwent cardiac surgery and had perioperative SARS-CoV-2 infection, 30-day mortality was $34 \% .{ }^{11}$

Clinical studies have shown that in addition to severe acute respiratory distress syndrome, the coronavirus- 2 infection also affects micro-circulation, has prothrombotic state and can cause myocardial injury, even in patients without coronary artery disease. ${ }^{12,13}$ This may be one of the reasons for the high mortality among patients who undergo surgery and present COVID-19 in the perioperative period, particularly in CABG surgery, where there is also a higher incidence of elderly, hypertensive and diabetic patients.

While the COVID-19 pandemic continues to increase globally, measures to control SARS-CoV-2 infection and patient safety need to be established to maintain cardiovascular surgery, even if in small numbers. The consequences of delayed recognition of a patient with COVID-19 are significant. Protocols for triage, early diagnosis, isolation in specific areas and treatment of patients with COVID-19 with cardiovascular complications should be developed to minimize the risk of in-hospital transmission and greater safety for hospitalized patients without COVID-19 and healthcare professionals. ${ }^{14,15}$

A large number of operations were canceled or postponed due to interruptions caused by COVID-19. Coincidentally, our institution have reported an increased number of mechanical complications, that maybe related to decreased number of patients seeking for medical assistance. ${ }^{16}$

Studies conducted in the first months of the pandemic showed that if countries increased their normal surgical volume by $20 \%$, it would take an average of 45 weeks to balance the backlog of operations resulting from the interruption of COVID-19. ${ }^{9}$ Patients awaiting elective cardiac surgery need to be proactively managed, reprioritizing those with high-risk anatomy or whose clinical status is deteriorating. In this regard, governments must mitigate this heavy burden on patients by developing recovery plans and implementing strategies to safely restore surgical activity as soon as possible.

\section{CONFLICT OF INTERESTS}

The authors declare that there are no conflicts of interests.

\section{AUTHOR CONTRIBUTIONS}

Luis Alberto O. Dallan completed invitation and concept of the article. Luiz Augusto F. Lisboa completed drafting of the article. Luis Roberto P. Dallan competed critical revision of the article. Fabio B. Jatene finalized the approval of the article.

\section{ORCID}

Luis Alberto O. Dallan (D) http://orcid.org/0000-0002-8655-8966 Luiz Augusto F. Lisboa (D) https://orcid.org/0000-0002-2137-0604 Luis Roberto P. Dallan (D) http://orcid.org/0000-0001-8137-5434 Fabio B. Jatene (D) https://orcid.org/0000-0001-6175-5595

\section{REFERENCES}

1. Griffin KM, Karas MG, Ivascu NS, Lief L. Hospital preparedness for COVID-19: a practical guide from a critical care perspective. Am J Respir Crit Care Med. 2020;201(11):1337-1344.

2. Al-Jabir A, Kerwan A, Nicola M, et al. Impact of the coronavirus (COVID-19) pandemic on surgical practice-part 1. Int J Surg. 2020; 79:168-179.

3. George I, Salna M, Kobsa S, et al. The rapid transformation of cardiac surgery practice in the coronavirus disease 2019 (COVID-19) pandemic: insights and clinical strategies from a center at the epicenter. Ann Thorac Surg. 2020;110(4):1108-1118.

4. Haft JW, Atluri P, Ailawadi G, et al. Adult cardiac surgery during the COVID-19 pandemic: a tiered patient triage guidance statement. J Thorac Cardiovasc Surg. 2020;160(2):452-455.

5. Patel V, Jimenez E, Cornwell L, et al. Cardiac surgery during the coronavirus disease 2019 pandemic: perioperative considerations and triage recommendations. J Am Heart Assoc. 2020;9(13): e017042.

6. Khalil K, Sá M, Vervoort D, et al. Impact of the COVID-19 pandemic in coronary artery bypass graft surgery in Brazil: a nationwide perspective. J Cardiac Surg. 2021.

7. Mejia OAV, Borgomoni GB, Silveira LMV, et al. The arrival of COVID-19 in Brazil and the impact on coronary artery bypass surgery. J Cardiac Surg. 2021:jocs.15712.

8. Almeida A, Santo T, Mello M, et al. Repercussions of the COVID-19 pandemic on the care practices of a tertiary hospital. Ara Bras Cardiol. 2020;115(5):862-870.

9. COVIDSurg Collaborative. Elective surgery cancellations due to the COVID-19 pandemic: global predictive modelling to inform surgical recovery plans. Br J Surg. 2020;107(11):1440-1449.

10. Salenger R, Etchill EW, Ad N, et al. The surge after the surge: cardiac surgery post-COVID-19. Ann Thorac Surg. 2020;110(6): 2020-2025.

11. COVIDSurg Collaborative. Mortality and pulmonary complications in patients undergoing surgery with perioperative SARS-CoV-2 infection: an international cohort study. Lancet. 2020;396(10243): 27-38.

12. McFadyen JD, Stevens $\mathrm{H}$, Peter $\mathrm{K}$. The emerging threat of (micro) thrombosis in COVID-19 and its therapeutic implications. Circ Res. 2020;127(4):571-587.

13. Zheng YY, Ma YT, Zhang JY, Xie X. COVID-19 and the cardiovascular system. Nat Rev Cardiol. 2020;17:259-260.

14. COVIDSurg Collaborative. Global guidance for surgical care during the COVID-19 pandemic. Br J Surg. 2020;107(9):1097-1103.

15. Wood DA, Mahmud E, Thourani VH, et al. Safe reintroduction of cardiovascular services during the COVID-19 pandemic: from the North American Society Leadership. J Am Coll Cardiol. 2020;75(25): 3177-3183.

16. Dallan LRP, Dallan LAO, Lisboa LAF, et al. Increased number of ventricular septal rupture cases after acute myocardial infarction in 2020. J Card Surg. 2021;36(7):2253-2262.

How to cite this article: O. Dallan LA, F. Lisboa LA, P. Dallan LR, B. Jatene F. Impact of COVID-19 on coronary artery surgery: Hard lessons learned. J Card Surg. 2021;36: 3294-3295. https://doi.org/10.1111/jocs.15769 